\title{
When and how to use predictive biomarkers for corticosteroid treatment of septic shock
}

\author{
James A. Russell ${ }^{1,2}$
}

Keywords: Septic shock, Predictive biomarkers, Gene expression, Leukocyte

The decision to give glucocorticoids to patients who have septic shock is difficult because of conflicting randomized controlled trial (RCT) level I evidence. Nonetheless, there is some evidence of overuse of corticosteroids in septic shock.

Early cohort studies found that there was an acquired corticosteroid deficiency in septic shock. A subsequent RCT [1] found that corticosteroids lowered mortality in patients who had an abnormal (i.e., inadequate) response to adrenocorticotropic hormone $(\mathrm{ACTH})$ stimulation in septic shock. The ACTH stimulation test has false positives and false negatives and is not recommended for deciding whether or not to administer glucocorticoids in septic shock [2]. Two large multicentre RCTs of corticosteroids in adult septic shock had conflicting results; Ananne and colleagues [3] found significant benefit while Venkatesh and colleagues [4] found no effect of corticosteroids on mortality. The most recent Surviving Sepsis Campaign (published prior to Annane [3] and Venkatesh [4]) used a cautionary tone, recommending against corticosteroid use in patients who have responded adequately to norepinephrine [5]. Similarly, but in a more positive tone, the recent Guidelines for the Diagnosis and Management of Critical Illness-related Corticosteroid Insufficiency (CIRCI) [2] recommend for corticosteroids in patients who do not respond to norepinephrine in septic shock.

One reason for conflicting evidence regarding responses to corticosteroids in septic shock is that different patients have different genomic, transcriptomic, and proteomic profiles that define different responses to corticosteroids in septic shock. Alder and colleagues recently made the

\footnotetext{
Correspondence: Jim.Russell@hli.ubc.ca

${ }^{1}$ Centre for Heart Lung Innovation, St. Paul's Hospital and University of British Columbia, 1081 Burrard Street, Vancouver, BC V6Z 1Y6, Canada
}

2Division of Critical Care Medicine, Vancouver, BC V6Z 1Y6, Canada hypothesis that peripheral leukocyte glucocorticoid receptor (GCR) expression and serum cortisol levels correlate with the response to glucocorticoids in pediatric septic shock (REF). They measured these biomarkers in a modest size prospective cohort $(n=164)$ of children who had systemic inflammatory response syndrome (SIRS), sepsis, or septic shock. The GCR expression levels were lower and the serum cortisol levels were higher in patients who had poorer outcomes. Where does this study leave the clinician who cares for patients with septic shock?

Finding predictive biomarkers-i.e. pharmacogenomic, transcriptional, and proteomic biomarkers that identify patients with improved responses to an intervention-is the holy grail of septic shock management [6]. We found that a novel combination of serum cytokine levels predicted improved responses to glucocorticoid administration in adult septic shock [7]. However, our study and others were made using cohorts of non-randomized patients who were treated with glucocorticoids or were simply observational cohorts such as Alder and colleagues (REF). Accordingly, despite the potential uses of predictive biomarkers in septic shock, the Surviving Sepsis Campaign [5] does not recommend any predictive biomarkers.

Transcriptomics-or expression profiling-is the study of RNA transcripts that are produced by the genome in specific conditions at specific times in specific tissues. So transcriptomics is more complex and more dynamic than genomics in that our genome is set at conception while transcriptomics change hour by hour in septic shock. Transcriptomics advocates cite that an advantage of transcriptomics is that they are even more specific than genomics and thus are better candidate predictive biomarkers. However, septic shock transcriptomics studies face barriers for robustness, such as which tissue to sample when- 
septic shock is a very rapid process (leading to lead time bias in clinical studies) - and even establishing a gold standard for the diagnosis of septic shock [8]. Alder and colleagues used peripheral blood leukocytes-which express the GCR but are a surrogate for deeper tissues of interest-drawn within $24 \mathrm{~h}$ of onset of SIRS, sepsis, or septic shock and then measured GCR expression by conventional flow cytometry because they were studying a very limited number of expression transcripts. Several groups [9] have evaluated genomics or whole blood or specific leukocyte gene expression as diagnostic and prognostic biomarkers in septic shock. Transcriptomics has identified subtypes of acute kidney injury (AKI) [10], a common complication of septic shock.

What are the next steps for validation of GCR expression as a predictive biomarker of corticosteroid administration in septic shock? Corticosteroids need to be evaluated in $\mathrm{RCT}(\mathrm{s})$ that are adequately powered to detect a significant interaction between (1) GCR expression and (2) use-or not-of corticosteroids. Some would argue, in part because of the storied controversy of steroids in septic shock, for a second confirmatory RCT to validate a GCR expression predictive biomarker. Recently completed RCTs such as those by Annane and colleagues [3] and Venkatish and colleagues [4] are excellent choices for validation because both were rigorous, yet the former was "positive" while the latter was "negative". I suggest that if a GCR expression biomarker significantly predicted which patients responded positively to glucocorticoids in both RCTs, even steroid skeptics would be interested.

After such confirmation and prior to widespread clinical use, many would recommend regulatory approval of a clinically validated GCR kit.

We and others have similarly addressed predictive biomarkers such as genomics [11], cytokine levels [12], and proteomics for use of vasopressin in septic shock. This is relevant because vasopressin treatment is also controversial in septic shock; the largest RCTs $[13,14]$ of vasopressin in septic shock were "negative" but there were suggestions of efficacy in patients who had less severe septic shock [13]. Similarly, genomics of the $\beta 1$ adrenergic receptor could identify good responders to the first line vasopressor in septic shock, norepinephrine [15].

Let's actualize a future in which individual patient baseline profiling of pharmacogenomics, mRNA expression (e.g., GCR), and protein levels (e.g., cytokine and cortisol levels) could personalize treatment with corticosteroids, vasopressin, and norepinephrine in septic shock (Fig. 1) and even guide post-discharge care to decrease the readmission risk. This future is not far off but requires focused design, execution, and analysis of well-conducted predictive biomarker studies in already completed and future RCTs.

Infection: Precision Medicine's Teachable Moment

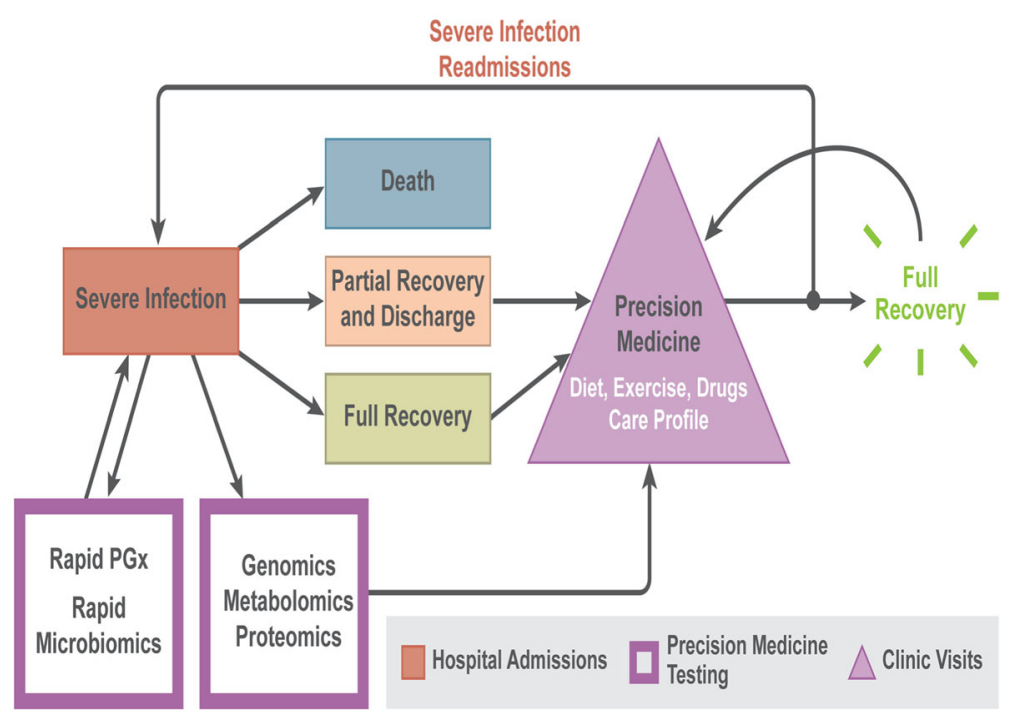

Fig. 1 In the future, patients who have severe infection will have rapid pharmacogenomics ( $P G x$ ), microbiomics, genomics, metabolomics, and proteomics ('omics) at presentation to guide acute management. Patients then die, have a partial or full recovery, and are discharged. After discharge, patients will have follow-up in a precision medicine clinic or office where the results of the 'omics will be discussed to select a diet, exercise, and drugs profile for each patient. This will enhance the chances for full recovery and reduce the risk of a readmission for severe infection 


\section{Abbreviations}

ACTH: Adrenocorticotropic hormone; AKI: Acute kidney Injury; CIRCl: Critical illness-related corticosteroid insufficiency; GCR: Glucocorticoid receptor; RCT: Randomized controlled trial; SIRS: Systemic inflammatory response syndrome

\section{Acknowledgements}

Not applicable.

\section{Funding}

Not applicable.

\section{Availability of data and materials}

Not applicable.

\section{Author's contributions}

JAR conceived and wrote the publication on his own. The author read and approved the final manuscript.

\section{Ethics approval and consent to participate}

Not applicable.

\section{Consent for publication}

Not applicable.

\section{Competing interests}

Dr. Russell reports patents owned by the University of British Columbia (UBC) that are related to PCSK9 inhibitor(s) and sepsis and related to the use of vasopressin in septic shock. Dr. Russell is an inventor on these patents. Dr. Russell is a founder, Director, and shareholder in Cyon Therapeutics Inc. (developing a sepsis therapy (PCSK9 inhibitor)). Dr. Russell has share options in Leading Biosciences Inc. Dr. Russell is a shareholder in Molecular You Corp.

Dr. Russell reports receiving consulting fees in the last 3 years from: Asahi Kesai Pharmaceuticals of America (AKPA; developing recombinant thrombomodulin in sepsis); La Jolla Pharmaceuticals (developing angiotensin II: Dr. Russell chaired the DSMB of a trial of angiotensin II from 2015 to 2017) — no longer actively consulting; Ferring Pharmaceuticals (manufactures vasopressin and was developing selepressin) - no longer actively consulting; Cubist Pharmaceuticals (now owned by Merck; formerly was Trius Pharmaceuticals; developing antibiotics) —no longer actively consulting; Leading Biosciences (was developing a sepsis therapeutic that is no longer in development)—no longer actively consulting; Grifols (sells albumin)—no longer actively consulting; CytoVale Inc. (developing a sepsis diagnostic) - no longer actively consulting.

Dr. Russell reports having received an investigator-initiated grant from Grifols (entitled "Is HBP a mechanism of albumin's efficacy in human septic shock?") that is provided to and administered by UBC.

\section{Publisher's Note}

Springer Nature remains neutral with regard to jurisdictional claims in published maps and institutional affiliations.

Received: 4 October 2018 Accepted: 1 November 2018

Published online: 21 November 2018

\section{References}

1. Annane D, Sebille V, Charpentier C, Bollaert PE, Francois B, Korach JM, Capellier G, Cohen Y, Azoulay E, Troche G, et al. Effect of treatment with low doses of hydrocortisone and fludrocortisone on mortality in patients with septic shock. JAMA. 2002;288(7):862-71.

2. Annane D, Pastores SM, Rochwerg B, Arlt W, Balk RA, Beishuizen A, Briegel J, Carcillo J, Christ-Crain M, Cooper MS, et al. Guidelines for the diagnosis and management of critical illness-related corticosteroid insufficiency (CIRCI) in critically ill patients (Part I): Society of Critical Care Medicine (SCCM) and European Society of Intensive Care Medicine (ESICM) 2017. Intensive Care Med. 2017:43(12):1751-63.

3. Annane D, Renault A, Brun-Buisson C, Megarbane B, Quenot JP, Siami S, Cariou A, Forceville X, Schwebel C, Martin C, et al. Hydrocortisone plus fludrocortisone for adults with septic shock. N Engl J Med. 2018;378(9):809-18.
4. Venkatesh B, Finfer S, Cohen J, Rajbhandari D, Arabi Y, Bellomo R, Billot L, Correa M, Glass P, Harward M, et al. Adjunctive glucocorticoid therapy in patients with septic shock. N Engl J Med. 2018;378(9):797-808.

5. Rhodes A, Evans LE, Alhazzani W, Levy MM, Antonelli M, Ferrer R, Kumar A Sevransky JE, Sprung CL, Nunnally ME, et al. Surviving Sepsis Campaign: international guidelines for management of sepsis and septic shock: 2016. Crit Care Med. 2017:45(3):486-552.

6. Prescott HC, Langa KM, Iwashyna TJ. Readmission diagnoses after hospitalization for severe sepsis and other acute medical conditions. JAMA. 2015;313(10):1055-7

7. Bentzer P, Fjell C, Walley KR, Boyd J, Russell JA. Plasma cytokine levels predict response to corticosteroids in septic shock. Intensive Care Med. 2016:42(12):1970-9.

8. Maslove DM, Wong HR. Gene expression profiling in sepsis: timing, tissue, and translational considerations. Trends Mol Med. 2014;20(4):204-13.

9. Pena OM, Hancock DG, Lyle NH, Linder A, Russell JA, Xia J, Fjell CD, Boyd JH, Hancock RE. An endotoxin tolerance signature predicts sepsis and organ dysfunction at initial clinical presentation. EBioMedicine. 2014;1(1):64-71.

10. Xu K, Rosenstiel P, Paragas N, Hinze C, Gao X, Huai Shen T, Werth M, Forster $C$, Deng $R$, Bruck $E$, et al. Unique transcriptional programs identify subtypes of AKI. J Am Soc Nephrol. 2017;28(6):1729-40.

11. Nakada TA, Russell JA, Wellman H, Boyd JH, Nakada E, Thain KR, Thair SA, Hirasawa H, Oda S, Walley KR. Leucyl/cystinyl aminopeptidase gene variants in septic shock. Chest. 2011;139(5):1042-9.

12. Russell JA, Fjell C, Hsu JL, Lee T, Boyd J, Thair S, Singer J, Patterson AJ, Walley KR. Vasopressin compared with norepinephrine augments the decline of plasma cytokine levels in septic shock. Am J Respir Crit Care Med. 2013;188(3):356-64.

13. Russell JA, Walley KR, Singer J, Gordon AC, Hebert PC, Cooper DJ, Holmes $\mathrm{CL}$, Mehta S, Granton JT, Storms MM, et al. Vasopressin versus norepinephrine infusion in patients with septic shock. N Engl J Med. 2008; 358(9):877-87.

14. Gordon AC, Mason AJ, Thirunavukkarasu N, Perkins GD, Cecconi M, Cepkova M, Pogson DG, Aya HD, Anjum A, Frazier GJ, et al. Effect of early vasopressin vs norepinephrine on kidney failure in patients with septic shock: the VANISH randomized clinical trial. JAMA. 2016;316(5):509-18.

15. Nakada TA, Russell JA, Boyd JH, Aguirre-Hernandez R, Thain KR, Thair SA, Nakada E, McConechy M. Walley KR: beta2-Adrenergic receptor gene polymorphism is associated with mortality in septic shock. Am J Respir Crit Care Med. 2010;181(2):143-9. 